\title{
Predicting long-term changes in marine benthic communities
}

\author{
John S. Gray and Hartvig Christie
}

Universitetet i Oslo, Institutt for marinbiologi og limnologi, avdeling marin zoologi og marin kjemi, P.B. 1064 Blindern, Oslo 3, Norway

\begin{abstract}
Analysis of long-term hydrographic data for the North Atlantic Ocean shows evidence of cycles with periods of 3 to 4,6 to 7,10 to 11,18 to 20 and 100 yr. There are known physical explanations for such cycles. Plankton data indicate that at least 3 to 4,6 to 7 and 10 to 11 yr cycles occur. Benthic data suggest 6 to 7 and 10 to 11 yr cycles are present, and evidence exists for a secular cycle. Not all species show or can be expected to show cyclic behaviour. Constancy of numbers through decades occurs at depths of over $100 \mathrm{~m}$ in some species and even with species at shallow depths. Whilst, using spectral analysis, cycles can be found in benthic data, cycles longer than those studied will undoubtedly interact giving rise to departures from predictions. Since there is evidence that periods of up to over $4000 \mathrm{yr}$ are to be expected there is little hope of accurate prediction of future trends in numbers. Instead, a monitoring strategy covering the same species over large areas is suggested. Departures from a common pattern may indicate local effects of pollutants.
\end{abstract}

\section{INTRODUCTION}

In examining effects of pollutants on marine benthic communities one has to be aware of natural long-term fluctuations which might wrongly be attributed to effects of the pollutant (e.g. Bowman, 1978). Yet many monitoring programmes are only done over relatively short time periods ( 4 to $5 \mathrm{yr}$ is long in this context). In this review we analyse some time series for marine benthic populations and examine the consequences of long-term cycles found for the prediction of long-term changes in such populations.

\section{SCALES OF LONG-TERM VARLATIONS IN THE SEA}

In analysing for regular variations in data sets it is not sufficient, for example, to cover a period of $10 \mathrm{yr}$ and find a simple harmonic wave over this period and then assume that a $10-y \mathrm{r}$ cycle is the rule. The next 10 yr data set may well not fit due to interference by even longer-term variations. Thus it is necessary to analyse really long-term data sets covering many decades to obtain some reasonable insight into periods of cycles. Light- and weather-ship observations extend back to the mid 1800 s and thus records of salinity and temperature variations in the oceans can be used to assess the sorts of scales of variability we can expect in marine data. Analysis methods have greatly improved recently with the advent of computers and spectral analysis programmes which can scan for wave periods in data sets (e.g. BMD programmes, Dixon, 1974, which we use in this paper). One well known cycle which need not be considered when analysing for long-term trends is the annual seasonal cycle. In typical data sets it does not matter whether mean annual numbers, summer maxima or winter minima are used the long-term trend is still apparent, particularly if running averages are used. Thus we confine our analyses to year-to-year variations and do not take seasonal data into account.

In an analysis of long-term temperature anomalies (variations from a long-term mean) on data for the North Atlantic Ocean using spectral analysis on moving averages, Maximov et al. (1972) found a multi- 
component cyclic character in temperature variations. The variations had periods of 6 to 7,10 to 12 and 18 to $20 \mathrm{yr}$, and these accounted for $50 \%$ of general longterm trends.

Maximov (1952) explains the 6 to $7 \mathrm{yr}$ cycle as the result of the free fluctuations (nutation) of the rotation pole of the ea th. The free nutations of the pole have a period of 14 mo giving a maximal deformation force at these times. The period of the earth's rotation about the polar axis is $12 \mathrm{mo}$, thus a maximal force will be generated at a certain point on the earth when the forces coincide, which is once every $7 \mathrm{yr}$. This force is called the Pole Tide. After removing the 10 to 12 and 18 to 20 -yr components, plots of the rotation pole radius-vector on the Greenwich Meridian against water temperature anomalies for 60 yr show remarkable agreement $(r=0.82)$ with a shift of 1 to $2 \mathrm{yr}$ (Maximov et al., 1972). The scale of change due to this cycle was of the order $\pm 0.6 \mathrm{C}^{\circ}$.

Similar 6 to 7 yr cycles occur in the Northern North Pacific Ocean, in mean sea level (Favorite and Ingraham, 1976); these were related to changed wind patterns, presumably with the same physical origin as Maximov's postulate.

The 10 to 12 -yr cycle is one of the best known of all, the solar or sun-spot cycle. The 11-yr cycle has been traced back to $647 \mathrm{BC}$ (Schove, 1965) and can be accurately predicted (Ottestad, 1979). The effect on the ocean is probably due to the fact that an increase in solar activity is accompanied by an increase in air pressure over high latitudes, whilst meridional pressure gradients decrease. This gives a breakdown in zonal atmospheric circulation and an intensification of meridional processes. Ultimately this leads to a strengthening of the N. Atlantic, Norwegian and E. Greenland currents and sea water temperature increases in the north and decreases in the south. The scale of change is around $\pm 0.2 \mathrm{C}^{\circ}$ (Maximov et al., 1972).

In addition to the 11-yr cycle there is a longer-term change in solar activity of 93 to 94 yr which also affects water temperature (Maximov, 1961; Waldemeier, 1961; Smirnov, 1967). From the beginning of this century to 1940, solar acitivity increased on this cycle giving an increased water temperature resulting from an intensification in the North Atlantic current flow and a less clear 11-yr trend over this period. Thus the whole North Atlantic Ocean was warm in the 1920-1930 period and colder in the '60s and '70s, especially in northern areas where a $1 \mathrm{C}^{\circ}$ change occurred.

The 18 to 20 yr-cycle is thought to be due to the longterm lunar tide (Pettersson, H., 1913; Pettersson, O., 1930; Maximov, 1959), with a period of $18.6 \mathrm{yr}$. The variations in the tidal force can be calculated accurately and can cause changes of $\pm 0.4 \mathrm{C}^{\circ}$ in mean temperatures (Maximov et al., 1972).

Thus we can expect that these cycles together will produce changes in the oceans. Maximov et al. (1972) have used 3 cycles ( 6 to 7,11 and 18.6 yr) to predict long-term temperatures in the Faroe-Shetland Channel (Fig. 1). Predicted data agree well with observed data $(r=0.73)$. It is clear that there are no obvious cycles but that regular changes occur. However, underlying the data are clear cyclical variations.

In an analysis of salinity data from the European Shelf areas of the North Atlantic, Dickson (1971) found correlations between high salinity anomalies from the long-term mean and establishment of an anomalous athmospheric circulation pattern, the Namias pattern (Namias, 1965). This pattern leads to advective changes in the eastern Atlantic giving an influx of salt to shelf areas. This atmospheric change also influences the deep currents and the inflow of water into the Baltic. Whilst the pattern has a roughly 6 to 7 -yr cycle, it is clear that other longer-period effects are confounding the patterns, and these may well be the 11,19 and secular cycles discussed previously.

A further cyclical trend in North Atlantic data is a 3 to 4-yr cycle (Maximov and Smimov, 1965). Colebrook and Taylor (1982) found a 3 to 4 and a 10 to 12 -yr cycle in salinity-temperature data but the data were out of phase with each other in the 3 to $4 \mathrm{yr}$ cycle. They related this cycle to changes in heat flux and evaporation under the influence of changes in the frequency of westerly weather.

Spectral analyses of salinity and temperature data taken from the Skagerrak at Torungen und Faerder

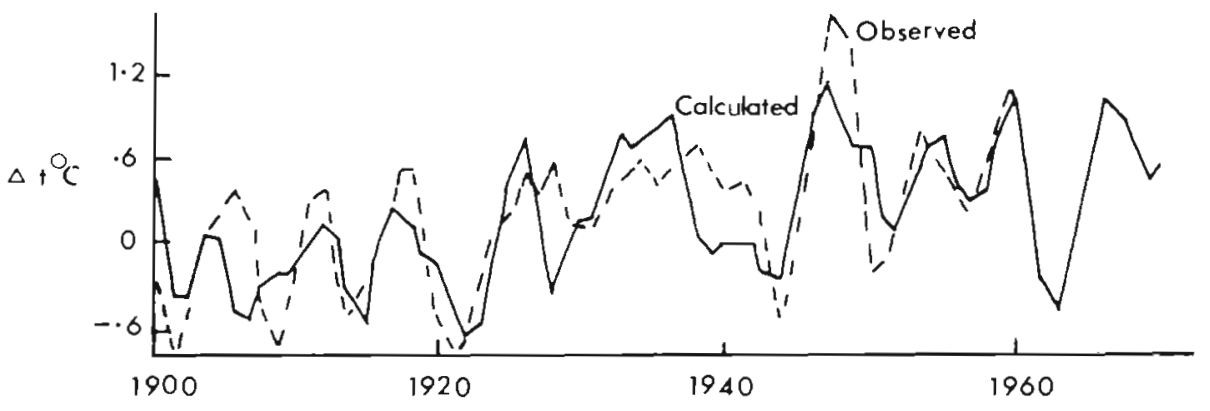

Fig. 1 Predicted and observed temperature anomalies over the Faeroe-Shetland ridge based on long-term cycles. (After Maximov et al., 1972) 
Fig. 2. Spectral analysis of temperature and salinity data from 2 stations in the Skagerrak (1960-1976). (Data provided by the Norwegian Oceanographic Data Centre)

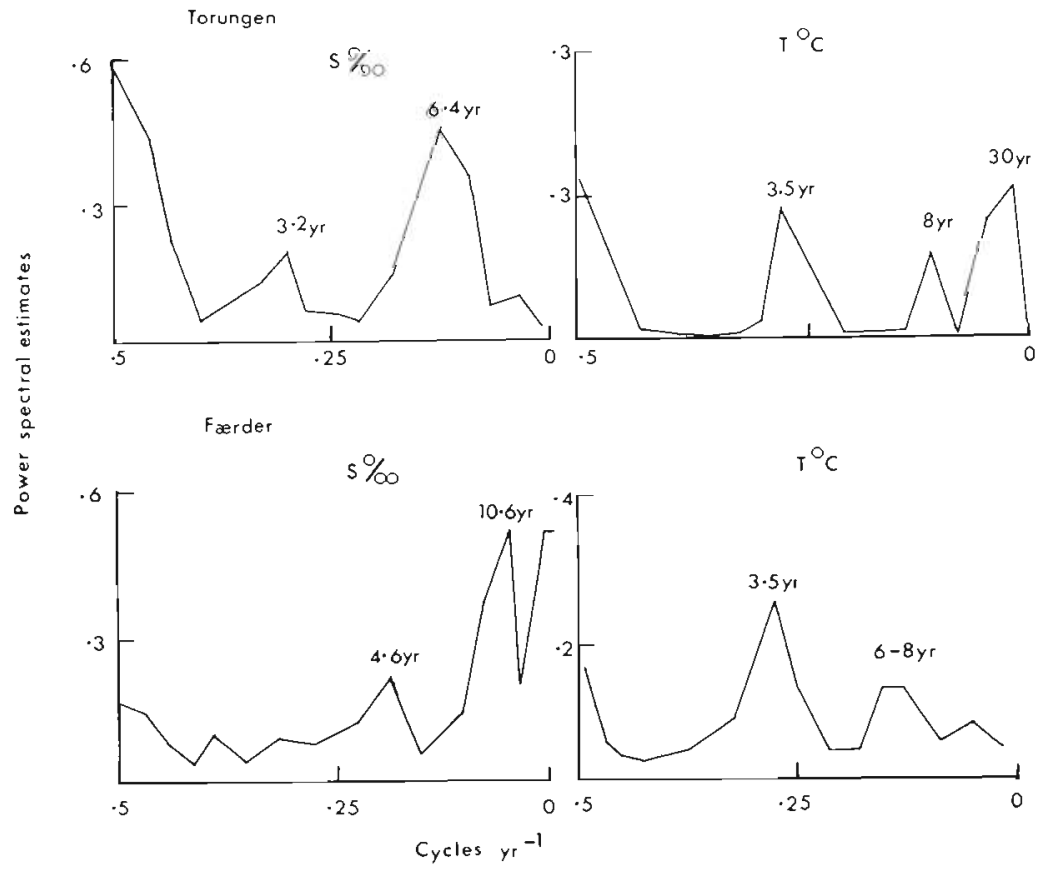

from 1960 to 1976 show (Fig. 2) clear 3 to 4 and 6 to 8-yr cycles. The data do not cover a long enough period to show longer cycles with any degree of certainty.

Concluding from these data sets there are known cycles in hydrographic conditions (salinity and temperature) over 3 to 4,6 to 7,10 to 12 and 18 to 20 -yr and $100 \mathrm{yr}$ with direct physical causes. The first 3 cycles could, however, be simple harmonies of the 18 to 20 -yr cycle, but this has not been tested. The cycles found must, however, influence the biology of the area affected.

\section{CONSEQUENCE OF HYDROGRAPHIC CYCLES ON BENTHOS}

One of the best long-term data sets in the marine environment is that of the Continuous Plankton Recorder (CPR). Colebrook and Taylor (1982) have analysed data on phyto- and zooplankton taxa from 1948-1980 and find evidence of cycles at 2 to $2.5,3$ to $3.6,5$ to 6.6 , and 10 to $20 \mathrm{yr}$. The 2 to 2.5 -yr cycle was explained as being due to interaction between the seasonal cycle and a longer cycle giving a beat-frequency at this wavelength. A simulation confirmed the interaction as the most likely cause of this cycle. Thus the clearly demonstrated hydrographic cycles also induce responses in phyto- and zooplankton. However, the latter, due to persistence of overwintering stocks, amplify the longer term wavelengths (Colebrook, 1981).

It is to be expected that known variations in hydro- graphic patterns ( 3 to 4,6 to 7,10 to 12 and 18 to 20 -yr cycles) will lead to direct effects on the dominant members of the phyto- and zooplankton. Population growth rates and production feeding rates etc. will all alter as a direct response to temperature and salinity changes. With benthic communities one can expect delayed responses due to the time-lags in organisms feeding directly on plankton, to settlement of organic matter from the plankton which lead to alterations in feeding rates of deposit feeders and ultimately to changes in reproductive rates of the benthos. Yet the coupling between plankton and benthos is poorly known and response times cannot be predicted. Species living at depths of $100 \mathrm{~m}$ or more in the Skagerrak are remarkably stable over long-time periods (Josefsson, 1981). Organic matter settling from surface layers is presumably degraded en route to such depths and thus there are no clear cycles to be expected in response to the hydrographic changes demonstrated. Boesch and Rosenberg (1981) have noted that there is a direct correlation between habitat constancy in physiocochemical conditions and fluctuations in benthic populations; intertidal and shallow subtidal populations show large fluctuations in numbers and have variable environmental conditions whereas the fauna from depths below $100 \mathrm{~m}$ show narrow fluctuations in a more constant environment. Thus such deep populations are not to be recommended in a pollution monitoring context because they respond so slowly to environmental change.

Yet even at shallow depths not all species in a community show large fluctuations. Buchanan (pers. 
comm.), examining populations of the burrowing decapod Calocaris macandrae from a muddy bottom at $90 \mathrm{~m}$ depth off the British east, coast found over a 10 -yr period a density of $13.7 \mathrm{~m}^{-2}$ with a coefficient of variation of only $5 \%$. C. macandrae is territorial and presumably if one individual dies it is replaced, thus maintaining a constant density.

Constant numbers over time may also occur in species with slow growth and recruitment rates. Svane and Lundälv (1982) report the ascidian Pyura tessulata from subtidal hard substrata in the Gullmarfjord, Sweden, which has had at 2 sites almost constant numbers showing a slight decline over a 10 -yr period.

The converse of the constant populations are opportunist species which with slight changes in the environment can rapidly respond by increasing population densities. In sediments the polychaete Capitella capitata can increase from 10 to over $400000 \mathrm{~m}^{-2}$ in the course of a 6 -wk period following disturbance of its habitat (Grassle and Grassle, 1974). In this species, colonisation of newly available habitat is rapid; the life-cycle is short and fecundity high, leading to the potential for rapid increases in population size. We know of no data linking fluctuations in numbers of individuals of species of opportunist to hydrographic cycles, but this could be possible.

In the Baltic Sea, there is a limited benthic fauna due to the low salinity; and in the Bothnian Sea, the amphipod Pontoporeia affinis is numerically highly dominant. This species was sampled over a large area of the Bothnian Sea at 19 stations with 5 to 10 grabs per station from 1961 to 1974 (Andersin et al., 1978).

Fig. 3 (and Fig. 4 a) shows that a 7 -yr sine curve fits the mean numbers almost perfectly. Whilst not over the same period, data for $P$. affinis from Askö in the Baltic Sea (Fig. 4b) and the south tip of Sweden at Hanö Bay

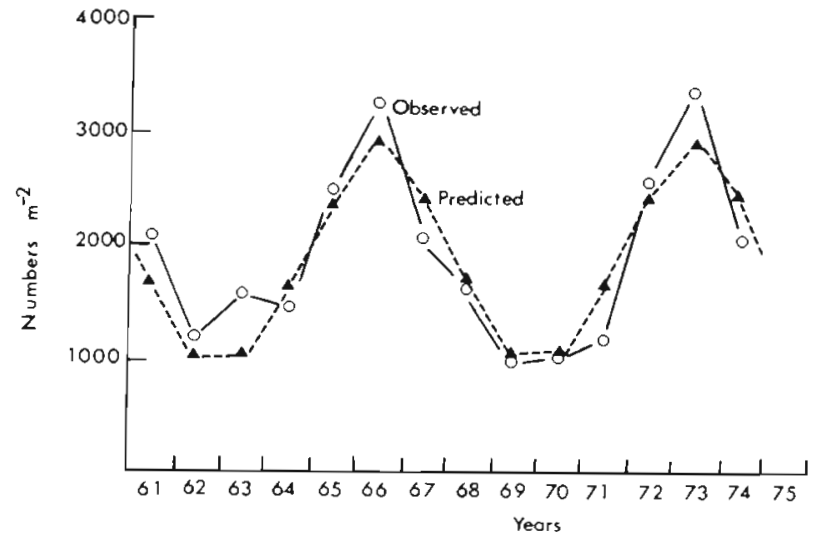

Fig. 3. Pontoporeia affinis. Variation in mean numbers in the Bothnian Sea, based on 19 stations and 5 to 10 grabs per station, and fitted sine curve with period of 7 yr. (Data from Andersin et al, 1978)

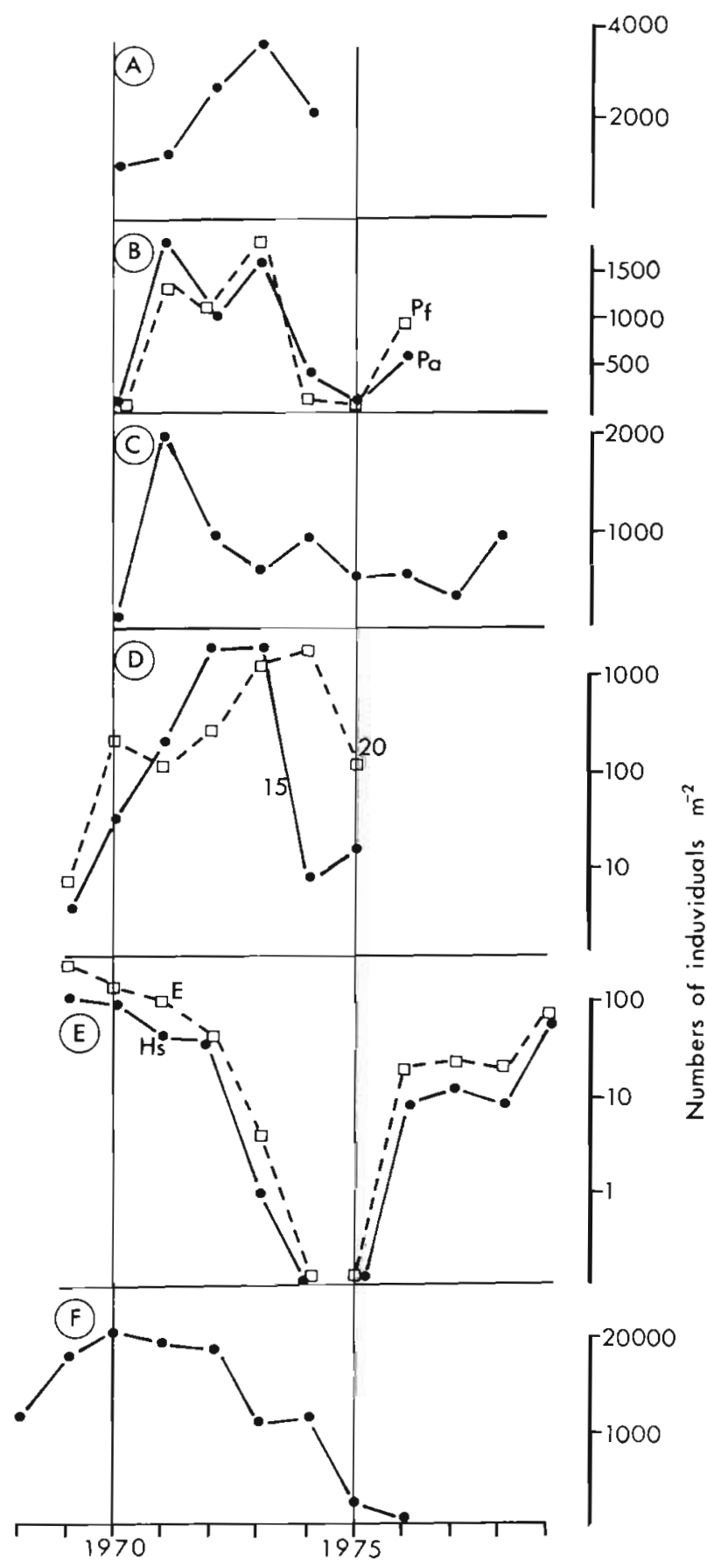

Fig. 4. Variations in numbers of benthic organisms. (a) Pontoporeia affinis in the Bothnian Sea. (Data from Andersin et al., 1978). (b) P. femorata, P. affinis at Askö, Sweden. (Data from Cederwall, unpubl.). (c) P. affinis in Hanö Bay, Sweden (Data from L. E. Persson, unpubl.). (d) Ciona intestinalis in Gullmarfjord, Sweden, at 15 and $20 \mathrm{~m}$ depth. (Data from Lundälv, unpubl.). (e) Harmothoe sarsi and Echiurus echiurus in the German Bight. (Data from Rachor, 1980). (f) Paronychocamptus nana in an enclosed estuarine area, Belgium. (Data from Heip, 1980) 
(Fig. 4c) show data with low values in 1970, high values in 1971-73 and a low in 1974-75 revealing approximate agreement with Bothnian Sea data with perhaps a slightly different period being earlier in Askö which is south of the Bothnian Sea.

Remarkably, other long-term data sets also show similar patterns: data on Ciona intestinalis at 2 stations in the Gullmarfjord (Fig. 4d): on Harmothoe sarsi and Echiurus echiurus (Fig. 4e) from the German Bight; and on the copepod Paronychocamptus nana from a lagoon on the Belgian coast (Fig. 4f). Pontoporeia affinis in the 3 areas and $C$. intestinalis show, in general, lows in 1969, 1970; highs in 1972-73; and a low again in $1974-76$. This suggests a 6 to 7 yr cycle. The other pattern is highs in 1970 and lows in 1974-75, and highs again in 1979-80 with cycles more approaching 10 to 11 yr (perhaps H. sarsi, E. echiurus and P. nana). None of these data are of a long enough period to allow spectral analysis.

Off the N.E. coast of Britain, Buchanan et al. (1978) recorded a change in the composition of the benthos at $70 \mathrm{~m}$ depth in 1970 coincident with many of the changes above. Buchanan noted a sudden $1 \mathrm{C}^{\circ}$ rise over the long-term mean sea-water temperature in 1970. Thus the changes can probably be linked to the known cycles of salinity and temperature.

Walker (1956) has shown that the quantity and ratio of species of Laminaria around Scotland varied with an 11-yr cycle which he correlated with the sun-spot cycle. André (1970) has suggested that macroalgae in the Gulf of Gascony show a secular cycle with minima around the turn of the century and maxima around 1944-45 for Fucus spiralis, F. ceranoides, Pelvetia canaliculata. F, vesiculosus, Ascophyllum nodosum also show a change of range in tidal height, and $F$. spiralis, $F$. vesiculosus, $F$. serratus, $P$. canaliculata, and Himanthalia elongata changed their biogeographic range during the cycle. Further evidence of such cycles has been provided during the 17th Marine Biology
Symposium at Brest, France (papers by Herman and Heip, Rees and Walker, and Eleftheriou and Basford, Océanologica Acta, in press). Table 1 summarizes the data.

Thus there is good evidence, albeit from a limited number of studies, that many benthic species do respond to long-term hydrographic cycles. It cannot be expected, however, that all species in a community will show such response. In a typical sediment community of 100 species only a few are opportunists, but their response is extremely short-term (weeks). There are probably 8 to 12 species of moderate abundance with numbers appropriate for statistical analysis, whereas the majority of the species (60 to $70 \%$ usual) are rare with low abundance. Causes of rareness are many and probably can never be unequivocably explained, hence Gray and Pearson (1982) suggest objective methods for deciding on a suite of 8 to 12 responsive species which can be used in sedimentary monitoring programmes. Lewis (1976) has analysed extensively the criteria for isolation of species suitable for monitoring on rocky shores.

From these analyses one can suggest that there will be a number of species in most benthic communities which show responses to long-term hydrographic cycles. One cannot, however, expect that because a population has shown a regular cycle for one 7-yr period that it will continue to do so. Other long-term influences will be expected to influence the species.

In order to illustrate just the sorts of complexities to be expected, Ottestad (1979) has suggested that all time-dependent variables are affected by the energy emitted by the sun. He suggests that this energy stream can be described by a linear function of sine (at) and cosine (at), where $\mathrm{a}=2 \mathrm{k} / \mathrm{L} ; \mathrm{t}=$ time; $\mathrm{k}=1,2,3$, etc. Based on analyses of many data sets, Ottestad maintains $\mathrm{L}$ is 4048 yr and all cycles are parts of this value. Thus, according to Ottestad, the sunspot species is made up of 11 components varying from 5.47 to $92 \mathrm{yr}$.

Table 1. Hydrographic cycles with examples of species showing similar cycles

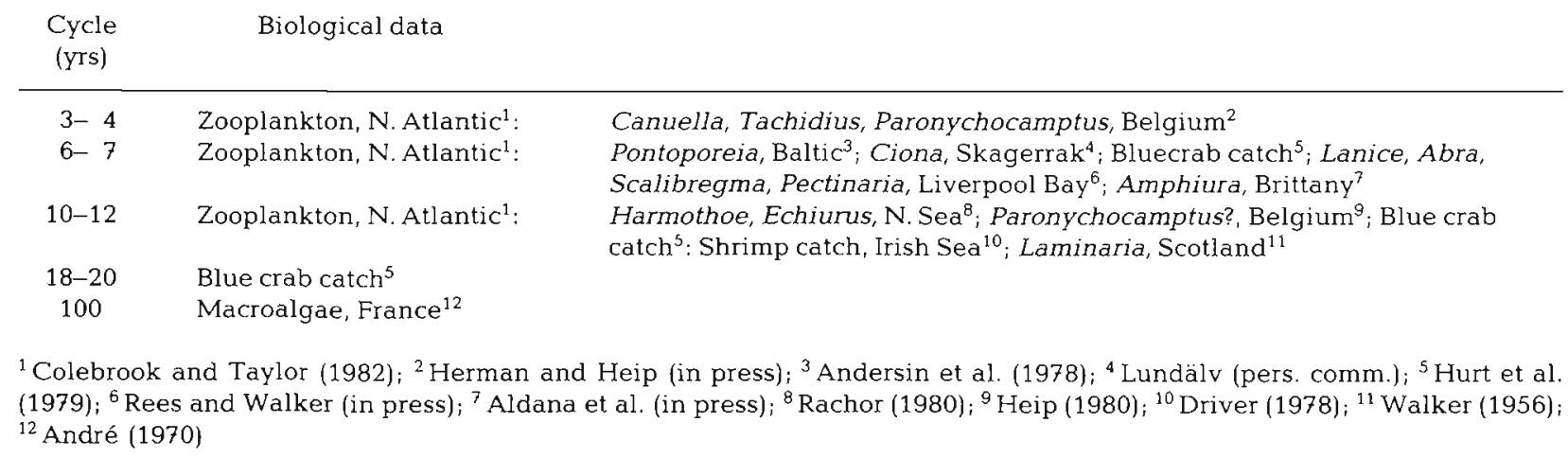

${ }^{1}$ Colebrook and Taylor (1982); ${ }^{2}$ Herman and Heip (in press); ${ }^{3}$ Andersin et al. (1978); ${ }^{4}$ Lundälv (pers. comm.); ${ }^{5}$ Hurt et al. (1979); ${ }^{6}$ Rees and Walker (in press); ${ }^{7}$ Aldana et al. (in press); ${ }^{8}$ Rachor (1980); ${ }^{9}$ Heip (1980); ${ }^{10}$ Driver $(1978) ;{ }^{11}$ Walker (1956); ${ }^{12}$ André (1970) 


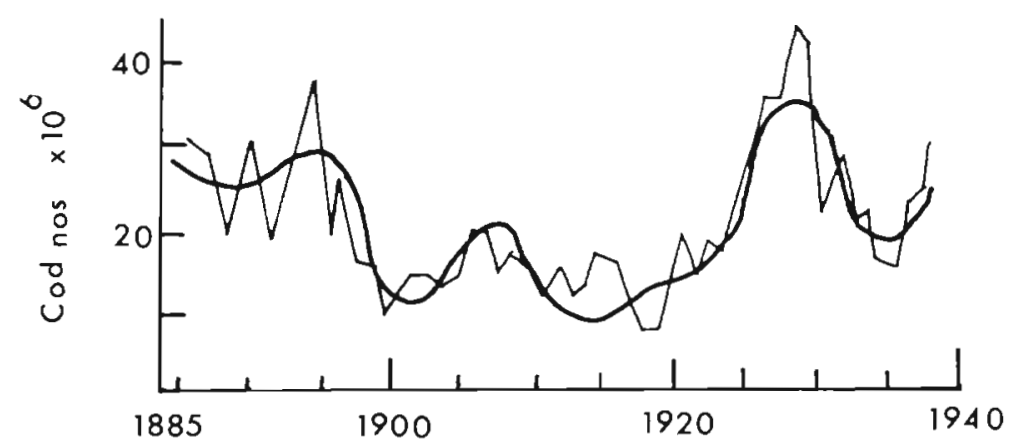

Fig. 5. Cod catch at the Lofoten fishery, Norway (jagged line) and pool curves of periodicities in widths of annual rings in pine trees in Vestfjord. (Data from Ottestad, 1942)
Ottestad (1942) has shown a most interesting comparison of the yield of cod in the Lofoten fishery and periodicities in the widths of annual rings in pine trees in the same region. Using the tree data, Ottestad fitted cycles of periods $57,23,17.5$, and $11 \mathrm{yr}$ each with different phases in any given year. The summed curves were fitted by least squares to the data on fish catches $(\mathrm{r}==0.84)$; they are shown in Fig. 5. There is clear evidence, therefore, that climatic cycles affect trees and fish stocks in the same area. Similarly, Cushing (1972) has demonstrated that recruitment in the ArctoNorwegian cod stock varies with changes in wind strength and direction between the Iceland low and the Azores high pressure areas.

Hurt et al. (1979) have shown by spectral analysis of blue crab landings for a 50-yr data set that cycles of 6.8 , $8.6,10.7$ and 18 yr occur. The data are again in keeping with the periodicities of the known long-term hydrographic cycles. Based on these data, compound sine curves using all cycles were produced and predictions of the catch made. The data fitted the observations well and predictions of crab landings have been made up to 1990. Similarly Driver (1978) related catches of shrimp landings over a 10-yr period to the sunspot cycle and suggests the sun-spot number alone can be used to predict future catches. The danger is that longer-term cycles are not expected and the data may rapidly depart from prediction due to interference of such cycles. If Ottestad is correct and cycles in excess of $100 \mathrm{yr}$ are to be expected then prediction of future trends in marine data becomes almost impossible.

\section{A MONITORING STRATEGY}

Yet we believe there are ways to overcome the difficulties. Our strategy is, having accurately established the annual cycle over a 3 -yr period, to survey a wide area a few times per year only. Then if one site is out of phase with the cycles at the other sites further investigation is needed to establish whether or not this is a local pollution effect. Christie (in press) has shown the approach taken. The choice of community land species) analysed is critical. We use an ascidian community on vertical subtidal hard substrata which shows similar faunal composition for the Swedish west and Norwegian south coasts in the Skagerrak. This community has been studied by Lundälv and Svane (1982) for over 10 yr in the Gullmarfjord and by us since 1978 (Christie, 1980), giving an extensive monitoring programme for the Skagerrak (Fig. 6). This is broadly similar to Lewis' (1976) rocky-shore monitoring scheme except that Lewis recommends study of factors affecting recruitment rather than population numbers.

Soft-sediment communities are more variable spatially over large areas than are the rock communities (Gray, 1981), and it is difficult to envisage a programme comparable to the above covering sediments. Here one possible strategy is to examine microgrowth bands in species of bivalves (Rhoads and Panella, 1970; Richardson et al., 1980) since on can retrospectively monitor changes in growth over short time intervals for periods of the length of life of the bivalves
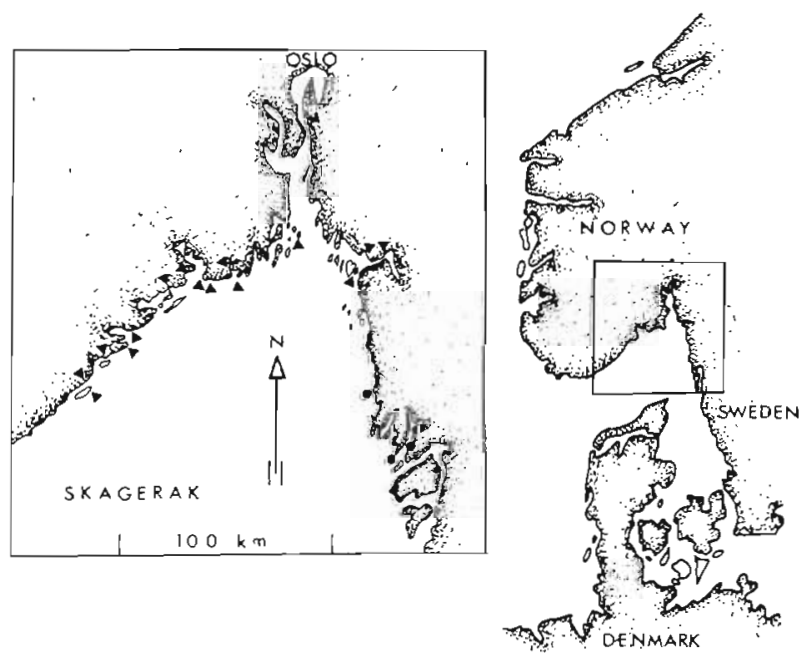

Fig. 6. Localities covered by sub-tidal hard-bottom monitoring programme in the Skagerrak. Arrows: Norwegian sites $\mathrm{H}$. Christie UiOslo; dots: Swedish sites, T. Lundälv, Kristinebergs Marine Biological Station, Fiskebäckskil, Sweden 
which is often in excess of 10-yr. It is, however, necessary to understand how the bands are established and the relationship to the annual gametogenetic cycle for interpretation of the bands. The bands are supposedly laid down in response to lunar cycles, but even species down at $30 \mathrm{~m}$ depth in the tideless Oslofjord have bands. Shallow depths were, earlier in this paper, suggested as being the areas where monitoring should be concentrated, and here microgrowth bands are found in many species. Here then is a sensitive technique that can be applied over spatial and temporal scales for retrospective monitoring.

In conclusion, predicting long-term changes in benthic communities is an unattainable goal due to the extremely long period cycles expected. Cycles may be apparent, but it cannot be expected that the cycle will be repeated since longer-term trends will interfere.

Acknowledgements. We thank the Norwegian Oceanographic Data Centre (NOD) for access to salinity and temperature data for the Skagerrak. We give special thanks to Thomas Lundälv, Ib Svane, Lars Erik Persson, and Hasse Cederwall for allowing us to use some of their unpublished data in Fig. 5. Age Larsen ran the spectral analyses and we are grateful to him.

\section{LITERATURE CITED}

Aldana, D., Glemarec, M., Menesguen, A., Princz, D., Seaman, M. (in press). Evolution temporelle de la macrofaune des satles envasés de la baie de Concarneau (Bretagne, France). (17th European Marine Biology Symposium, proceedings) Oceanol. Acta

Andersin, A.-B., Lassig, J., Parkkonen, L., Sandler, H. (1978). Long-term fluctuations of the soft-bottom macrofauna in the deep areas of the Gulf of Bothnia 1954-1974; with special reference to Pontoporeia affinis Lindström (Amphipoda). Finnish mar. Res. 244: 137-144

Andrê, F. (1970). Causes possible des variations (de petit ou de grande amplitude) dans le temps, de la végétation marine. C. r. hebd. Séanc. Acad. Sci., Paris

Boesch, D., Rosenberg, R. (1981). In: Barett, C. W., Rosenberg, R. (ed.) Stress effects on natural ecosystems. Wiley, London

Bowman, R. S. (1978). Dounreay oil spill: major implications of a minor incident. Mar. Pollut. Bull. 9: 269-273

Buchanan, J. B., Sheader, M., Kingston, P. R. (1978). Sources of variability in the benthic macrofauna off the South Northumberland coast, 1971-76. J. mar. biol. Ass. U. K. 58: 191-210

Christie, H. (1980). Methods for ecological monitoring: biological interactions in a rocky subtidal community. Helgoländer Meeresunters. 33: 473-483

Christie, H. (in press). Natural fluctuations in a rocky subtidal community in the Oslo Fjord (Norway). (17th European Marine Biology Symposium, proceedings). Océanol. Acta

Colebrook, J. M. (1981). Continuous plankton records: persistence in time-series of annual means of abundance of zooplankton. Mar. Biol. 61: 143-149

Colebrook, J. M., Taylor, A. H. (1982). Significant time-scales of long-term variability in the plankton and the environment. ICES Symposium 'Biological Productivity of Conti- nental Shelves of the Temperate Zone of the North Atlantic'. Wood's Hole March 1982 Contribution 19: 1-7

Cushing, D. J. (1972). The production cycle and the numbers of marine fish. Symp. zool. Soc. Lond. 29: 213-232

Dickson, R. R. (1971). A recurrent and persistent pressure anomaly. Dt. hydrogr Z. 24: 97-119

Dixon, W. J. (ed.) (1974). Biomedical computer programs. University of California Press, Berkeley

Driver, P. A. (1978). The prediction of shrimp landings from sunspot activity. Mar. Biol. 47: 354-361

Eleftheriou, A., Basford, D. J. (in press). Fluctuations in the macrobenthos and fish populations in a sandy bay. (17th European Marine Biology Symposium, proceedings) Océanol. Acta

Favorite, F., Ingraham, W. J. (1976). Sunspot activity and oceanic conditions in the northern North Pacific Ocean. J. oceanogr. Soc. Japan 32: 107-115

Grassle, J. F., Grassle, J. P. (1974). Opportunistic life-histories and genetic systems in marine benthic polychaetes. $J$. mar. Res. 32: 253-284

Gray, J. S. (1981). The ecology of marine sediments. Cambridge studies in modern biology 2. Cambridge University Press, Cambridge

Gray, J. S., Pearson, T. H. (1982). Objective selection of sensitive species indicative of pollution-induced change in benthic communities. 1. Comparative methodology. Mar. Ecol. Prog. Ser. 9: 111-119

Heip, C. (1980). Meiobenthos as a tool in the assessment of marine environmental quality. Rapp. P.-v. Réun. Cons. int. Explor. Mer 179: 182-187

Herman, P. M. J., Heip, C. (in press). Long-term dynamics of meiobenthic populations. (17th European Marine Biology Symposium, proceedings) Océanol. Acta

Hurt, P. R., Libby, L. M., Pandolpi, L. J., Levine, L. H. (1979). Periodicities in blue crab population of Chesapeake Bay Clim. Change 2: 75-78

Josefsson, A. (1981). Persistence and structure of two deep macrobenthic communities in the Skagerrak (west coast of Sweden). J. exp. mar. Biol. Ecol. 50: 63-97

Lewis, J. R. (1976). Long-term ecological surveillance: practical realities in the rocky littoral. Oceanogr. mar. Biol. A. Rev. 14: 371-390

Maximov, I. V. (1952). On the pole tide in the ocean and atmosphere. Reports An SSSR 86: 673-676

Maximov, I. V. (1959). Long-period lunar and solar tides in the high latitude seas. Scient. Notes LVIMU 13: 3-38

Maximov, I. V. (1961). Secular cycle of solar activity and the North Atlantic Current. Okeanologija 1: 206-212

Maximov, I. V., Smirnow, N. P. (1965). On the causes of longterm variations of Gulf Stream activity. Okeanologija 5: $210-221$

Maximov, I. V., Sarukhanyan, E. I., Smirnov, N. P. (1972). Long-term variations of the $N$. Atlantic current and their possible causes. Rapp. P.-v. Réun. Cons. int. Explor. Mer 162: $159-166$

Namias, J. (1965). Short-period climatic fluctuations. Science, N.Y. 147: 696

Ottestad, P. (1942). On periodical variations in the yield of the Great Sea Fisheries and the possibility of establishing yield prognoses. FiskDir. Skr. (Ser Havunders.) 7: 1-11

Ottestad, P. (1979). The sunspot series and biospheric series regarded as results due to a common cause. Meld. Norg LandbrHøisk. 58 (9): 1-20

Pettersson, H. (1913). Long periodical variations of the tide generating force. Publs Circonst. Cons. perm. int. Explor. Mer 65: 1-23

Pettersson, O. (1930). The tidal force. Geogr. Annlr 12 
Rachor, E. (1980). The inner German Bight - an ecologically sensitive area as indicated by the bottom fauna. Helgoländer wiss. Meeresunters. 33: 522-530

Rees, E.I.S., Walker, A. J.M. (in press). Variation in the Abra community in the Liverpool bay. (17th European Marine Biology Symposium, proceedings) Océanol. Acta

Richardson, C. A., Crisp, D. J., Runham, N. W, Gruffydd, L. D. (1980). The use of tidal growth bands in the shell of Cerastoderma edule to measure seasonal growth rates under cool temperature and sub-arctic conditions. J. mar. biol. Ass. U. K. 60: $977-989$

Rhoads, D. C., Panella, G. (1970). Use of molluscan shell growth patterns in ecology. Lethaia 3: 143-161
Schove, D. J. (1965). The sunspot cycle, 649 B. C. to A. D. 2000. J. geophys. Res. 60: 127-146

Smirnov, N. P. (1967). Solar activity and the Gulf Stream. Documents of Fishery Research of the Northern Basin 10: $70-82$

Svane, I., Lundälv, T. (1982). Persistence stability in ascidian populations: long-term population dymamics and reproductive pattern of Pyuna tessellata (Forbes) in Gullmarfjorden on the Swedish west coast. Sarsia 67: 249-257

Waldemeier, M. (1961). The sunspot activity in the years 1610-1960. Zürich

Walker, F. T. (1956). Periodicity of the Laminariaceae around Scotland. Nature, Lond. 177: 1246

This review was submitted to the editor; it was accepted for printing on April 20, 1983 